\title{
NSW LEAD MANAGEMENT PROGRAM IN BROKEN HILL
}

David Lyle

Department of Rural Health

University of Sydney, Broken Hill

Bill Balding, Hugh Burke and Steven Begg

Far West Area Health Service

This paper describes the development of the NSW Lead Management Program in Broken Hill, which is a joint project of the Far West Area Health Service and the NSW Environment Protection Authority. The program illustrates the successful application of public health principles to deal with an environmental health problem in a rural setting.

\section{BACKGROUND}

Broken Hill is a mining town located in the semi-arid region of western NSW. It is the site of one of the world's richest deposits of silver, lead, and zinc, where mining activities began in 1883 and continue to the present day. ${ }^{1}$ In the early days, lead poisoning was a cause for concern, which was viewed primarily as an occupational health hazard. ${ }^{2}$ The recommissioning of open-pit mining, and a drought in the late 1980s, saw the rise in veterinary notifications of lead poisoning in dogs; and a survey conducted among pre-school aged children in 1991 showed that one quarter of children had blood lead levels above the then revised National Health and Medical Research Council level for concern $(25 \mathrm{mg} / \mathrm{dL}))^{3,4}$

It was not coincidental that a re-evaluation of the lead as a public health issue occurred at that time. The emerging evidence on the health effects of lead-particularly in pre-school aged children - and the downward revision of NHMRC's level of concern, motivated the newly revitalised public health workforce in NSW to take a fresh look at the problem. ${ }^{5}$

In early 1992, the NSW Department of Health funded an investigation into the lead issue in Broken Hill. The investigation revealed that a lack of a single source of lead, and its widespread distribution in and around the city, meant that cleaning up the whole town and preventing the further release of lead into the environment was not feasible as a primary strategy. The situation required a more targeted approach, which dealt with specific sources that could be linked to children with a high blood lead level; both reducing the amount of hazard at the probable source, and modifying the rate or spatial distribution of release of lead that remained.

This targeted approach was supported by a range of educational, behavioural and environmental interventions aimed at children, which were specifically reinforced for young children with high blood lead levels. These interventions were designed to prevent the likelihood of lead already available in the environment being taken up by children. Medical intervention using chelation therapy was, at the time, the initial treatment of choice for the few children who had very high blood lead levels.

\section{LEAD MANAGEMENT PROGRAM}

In 1994 the management strategy was formally launched, supported by a joint investment between the NSW Department of Health and the NSW Environmental Protection Authority over seven years until mid 2001. The lead management program aims to reduce blood lead levels in Broken Hill children to that observed in noncontaminated areas elsewhere in Australia.

The lead management program incorporates five main activities:

- monitoring and case-finding

- case management

- public education and health promotion

- remediation of public land

- evaluation, research and development.

Governance is provided through a Working Group set up with representation from:

- Far West Area Health Service

- NSW Environment Protection Authority

- Australian Inland Energy and Water

- Pasmino Mining

- Construction, Forestry, Mining and Energy Union

- community-based early childhood services

- the local member of the NSW Legislative Assembly

- Broken Hill City Council mayor and councillors

- NSW Department of Mineral Resources

- general practice in the local area.

Monitoring and case-finding activities underpin the entire strategy. Since 1994 a voluntary screening service has been offered to families with young children on a weekly basis for blood testing, to answer questions, and to give information and advice about safe lead practices and behaviours.

Initially young children identified with blood lead levels $\geq 25 \mathrm{mg} / \mathrm{dL}$ were referred for more intensive management to effect a rapid reduction of their lead intake and blood lead levels. Children with less elevated blood lead levels $(15-24 \mathrm{mg} / \mathrm{dL})$, were offered intensive case management.

Intensive case management included a home visit by the 'lead' nurses to: 
- identify potential sources and exposure pathways for an affected child: for example, environmental sampling in and around the home; behavioural assessment concerning lead safe behaviours;

- provide advice and support for parents to take action to reduce their children's exposure to, and intake of, lead.

For children with substantially elevated blood lead levels, parental action was supported by a systematic removal of sources of lead in the home environment. Home remediation included:

- removing ceiling dust;

- removing or covering contaminated soil around the home;

- stabilising flaking lead-based paints;

- cleaning or replacing carpets and cleaning soft furnishings;

- addressing structural problems in the home that did not adequately prevent dust ingress (that is, in walls, ceilings, floors).

Home remediation was subject to scientific evaluation to determine how effective it was in reducing blood lead levels.

With regard to public education and health promotion, the Broken Hill community was kept informed and involved in the lead issue through regular media reports; and through other promotional activities in preschools and to relevant groups such as new parents, pregnant women, and health professionals. Other programs aimed at modifying behaviour included curriculum-based lead education in schools, and training of local government organisations and private sector enterprises: that is, council, nurseries, hardware stores, and tradesmen. The purpose of these activities was to raise community awareness of the lead issue, to promote and encourage use of available lead management services, and to provide information and advice to parents about safe lead behaviours. Public education and health promotion activities supported the importance of increasing community understanding, and thereby enhancing commitment and responsibility to managing the health risk of lead across all sectors.

An assessment of public lands was organised to map lead concentrations and soil stability at individual sites, which were then categorised according to the perceived risk to adjacent residential areas by dispersion or direct contact. This component of the program is viewed as an adjunct to the effective handling of pre-existing contamination in and around homes and the adoption of safe lead behaviours within the community.

A population-based register of preschool children presenting for blood lead screening has been in operation since 1991 and contains information on birth cohorts from 1987. Data from that register forms part of the evaluation strategy for the lead management program. Research is used to report on the development and outcomes of the lead remediation program, to develop an understanding of the sources and pathways of lead exposure in Broken Hill, to evaluate specific components of the lead program, and to respond to emerging issues.

Following the success of the initial activity with children with established lead problems, the program is now moving to establish early intervention strategies andwith a reduced need for, and emphasis on, home remediation-to increase its investment in communitywide work. For example, in 1996 the monitoring program was extended to include the measurement of lead levels in pregnant women and neonates (via cord blood) in order to identify families where early intervention was indicated before or around the birth of the child. It was argued that modifying environmental hazards in and around the home, and adopting more appropriate safe lead behaviours from birth, may reduce a baby's overall lead level and also obviate the need for later more expensive home remediation.

\section{THE FUTURE}

The joint investment by the NSW Department of Health and the NSW Environment Protection Authority over the past 10 years has been associated with a significant reduction in blood lead levels; and follows in the footsteps of other successful rural-based programs such as Port Pirie in South Australia. ${ }^{6}$ While the evaluation of data indicates that real progress has been made in dealing with the lead problem in Broken Hill, continued public health action is required to bring the current proportion ( 16 per cent) of young children with elevated blood lead levels $(15 \mathrm{mg} /$ $\mathrm{dL}$ and greater) down to the NHMRC target of five per cent. ${ }^{4}$ Further, the nature of the physical environment in Broken Hill means that the dispersion and redistribution of lead dust will continue to pose a potential hazard to young children for the foreseeable future. Thus, the public health imperative will demand an ongoing, organised response to the problem of lead in the city while significant numbers of young children live there.

\section{CONCLUSION}

The basic requirements for the future management of lead in Broken Hill will draw on public health principles, with an emphasis on hazard reduction and the prevention of ill-health, and its implementation will be achieved through cooperative action across sectors and with community participation.

\section{ACKNOWLEDGMENTS}

We wish to acknowledge the efforts of Dr Mark Jacobs and Dr John Hall, and Mr Andrew Phillips, who initiated 
this program in Broken Hill between 1990-1994; the staff of the Broken Hill Environmental Lead Centre; and the Working Party. We are grateful to Dr Stephen Corbett, Environmental Health Branch, for his continuing support and assistance.

\section{REFERENCES}

1. Solomon RJ. The Richest Lode, Broken Hill 1883-1988. Sydney: Hale and Iremonger, 1988.

2. Ashburton Thompson J. Report of Board appointed to inquire into the prevalence and prevention of lead poisoning at the Broken Hill Silver-Lead Mines. Sydney: NSW Legislative Assembly Government Printer Sydney, 1898.

3. Phillips A, Lyle DM, Reddan S, et al. Dealing with Lead in Broken Hill: Trends in blood lead levels in young children
1991-1999. Broken Hill: Department of Rural Health, University of Sydney, 2000. Unpublished.

4. National Health and Medical Research Council. Lead in Australians. Statement issued by the 115th session of NHMRC. Revision 1987 (103rd session) guidelines 2 June 1993.

5. Morey S. New Public Health Bulletin for NSW. NSW Public Health Bulletin 1990; 1: 1. Please refer to the Bulletin's subject and author indexes for reference to several articles on lead. These indexes are viewable at the Bulletin's Web site www.health.nsw.gov.au/public-health/phb/phb.html.

6. Maynard EJ, Calder IC, and Phipps CV, The Port Pirie lead implementation program. Review of progress and consideration of future directions, 1984-1993. Adelaide: South Australian Health Commission, 1993. Wt

\section{NSW HEALTH BECOMES A REGISTEREDTRAINING ORGANISATION}

\section{Ross Hartley}

Director, Rural Health Education \& Research Centre

New England Area Health Service, Tamworth

NSW Health has a strong commitment to providing learning and development services to the health workforce in NSW, including the public health workforce. In March 2000, the NSW Vocational Education and Training Accreditation Board (VETAB) issued NSW Health with a Certificate of Registration as a Registered Training Organisation (RTO) for three years. This registration was the culmination of a long process of cooperation and collaboration between the NSW Department of Health, the Area Health Services, and the New Children's Hospital. This article describes the process by which NSW Health became an RTO, and its method of delivering vocational learning and development services.

\section{BACKGROUND}

Before NSW Health achieved RTO status, vocational training was conceived, designed and delivered independently by the Department of Health, individual Area Health Services, and the New Children's Hospital. (Although a part of NSW Health, the Ambulance Service of NSW remains a separately registered RTO.) Some of these organisations were registered to provide training, but few courses were accredited. Throughout the 1990s there was a gradual trend towards the delivery of accredited vocational training, which encompassed the notions of recognition of prior learning, competencies, workplace assessment, and articulation to higher qualifications.

The suggestion that NSW Health should become an RTO was first canvassed in the mid-1990s. The challenge was to negotiate a successful collaboration among the autonomous health organisations, which was necessary for the accreditation process. While these organisations were all part of NSW Health, there was no common charter, and many were already registered with VETAB to provide accredited training. While the impetus for a single accreditation for the whole of NSW Health came initially from the Area Health Services and the New Children's Hospital, the success of the accreditation process was very much due to the coordination and support provided by the NSW Department of Health through its then Human Resources Policy and Strategy Unit.

\section{THE ACCREDITATION PROCESS}

Under section 22C of the Vocational Education and Training Accreditation Act 1990, VETAB registers organisations to:

- deliver vocational education and training (VET) courses

- provide assessment services

- issue qualifications.

To achieve and maintain RTO status, NSW Health must demonstrate compliance with the quality assurance and accreditation standards of national guidelines known as the Australian Recognition Framework (ARF). The Director-General and the Chief Executive Officers of the Area Health Services formally committed NSW Health to these standards in June 1999. The 12 ARF standards are listed in Table 1. The first seven standards (C1-C7) ensure that an RTO complies with quality, legislative and ethical requirements; while the remaining five standards (TD1TD5) ensure that an RTO has the ability to deliver on-site training and assessment to the standards. 